\title{
Interaction pathways and structure-chemical transformations of alginate gels in physiological environments
}

\author{
Martina Urbanova ${ }^{1 \#}$, Miroslava Pavelkova ${ }^{2 \#^{*}}$, Jiri Czernek', Katerina Kubova ${ }^{2}$, Jakub \\ Vyslouzil $^{2}$, Alena Pechova ${ }^{3}$, Dobromila Molinkova ${ }^{4}$, Jan Vyslouzil ${ }^{5}$, David Vetchy ${ }^{2}$, Jiri Brus ${ }^{1 *}$ \\ ${ }^{1)}$ Institute of Macromolecular Chemistry, Czech Academy of Sciences, Heyrovsky sq. 2, 16206 Prague 6, Czech \\ Republic \\ 2) University of Veterinary and Pharmaceutical Sciences, Faculty of Pharmacy, Department of Pharmaceutics, \\ Palackeho tr. 1946/1, 61242 Brno, Czech Republic \\ 3) University of Veterinary and Pharmaceutical Sciences, Faculty of Veterinary Hygiene and Ecology, Department \\ of Animal Protection, Welfare and Behaviour, Palackeho tr. 1946/1, 61242 Brno, Czech Republic \\ 4) University of Veterinary and Pharmaceutical Sciences, Faculty of Veterinary Medicine, Department of Infectious \\ Diseases and Microbiology, Palackeho tr. 1946/1, 61242 Brno, Czech Republic \\ 5) Department of Biochemistry, Faculty of Science, Masaryk University, Kotlarska 267/2, 611 37, Brno, Czech \\ Republic
}

AUTHOR EMAIL ADDRESSES:urbanova@imc.cas.cz, pavelkovam@vfu.cz, czernek@imc.cas.cz, kubovak@vfu.cz, vyslouzili@vfu.cz, pechovaa@vfu.cz,molinkovad@vfu.cz, 392336@mail.muni.cz, vetchyd@vfu.cz, brus@imc.cas.cz

\section{Table of Content}

Supporting Information SI1 - Preparation of alginate beads

Supporting Information S12 - Composition of alginate beads

Supporting Information SI3 - Morphology characterization

Supporting Information SI4 - Swelling capacity tests

Supporting Information SI5 - Dissolution tests

Supporting Information SI6 - Ex-vivo cytotoxicity tests

Supporting Information S17 - Solid-state NMR spectroscopy

Supporting Information SI8 - Scanning electron microscopy 


\section{Supporting Information SI1 - Preparation of alginate beads}

Materials: Aqueous solutions of $\mathrm{CaCl}_{2}, \mathrm{ZnCl}_{2}, \mathrm{MnCl}_{2}, \mathrm{SrCl}_{2}, \mathrm{BaCl}_{2}$, and $\mathrm{AlCl}_{3}\left(1 \mathrm{~mol} / \mathrm{dm}^{3}\right)$ were used as crosslinking agents. Calibration solutions were prepared using a dilution of $1000 \mathrm{mg} / \mathrm{L}$ stock reference solvent (Analytika, Prague, Czech Republic). Deionized water with a resistivity of $18 \mathrm{M} \Omega$ was used for all necessary dilutions. Vero cell line (ATCC CCL-81) in D-MEM medium (Dulbecco's Modified Eagle Medium, BioTech a.s., Prague, Czech Republic) supplemented with 10\% Fetal bovine serum (FBS) (HyClone ${ }^{\mathrm{TM}}$, USA), for evaluation cytotoxicity.

Sample preparation: Crosslinked alginate microbeads were prepared via external ionic gelation. A 6 wt.\% sodium alginate dispersion was prepared by homogenizing ALG_Na in purified water. The polymer was swelled in purified water ( $5 \mathrm{~min}$ ) at room temperature and subsequently homogenized at 13,000 rpm for 5 min using an Ultra-Turrax (T25 basic, IKA-Werke, Staufen, Germany). The dispersion volume was ultimately adjusted to $100 \mathrm{~mL}$ with purified water. The prepared homogenous dispersions were then extruded through a $0.7 \mathrm{~mm}$ diameter needle at a dropping rate of $2.0 \mathrm{~mL} / \mathrm{min}$ into a $1.0 \mathrm{M}$ hardening aqueous solution. The distance between the edge of the needle and the surface of the solution was 5.0 $\mathrm{cm}$. Microbeads were formed instantaneously and then were left in the crosslinking solution for $1 \mathrm{hr}$. The resulting beads were subsequently washed three times with purified water and dried at $25^{\circ} \mathrm{C}$ for $24 \mathrm{hr}$ in a cabinet drier (HORO - 048B, Dr. Hofmann GmbH, Ostfildern, Germany).

\section{Supporting Information SI2 - Composition of alginate beads}

The content of $\mathrm{Ba}, \mathrm{Sr}, \mathrm{Ca}, \mathrm{Zn}, \mathrm{Mn}, \mathrm{Al}$ in the prepared beads was determined using flame atomic absorption spectrometry. To digest the beads, $6 \mathrm{~mL}$ of nitric acid $(32.5 \% \mathrm{v} / \mathrm{v})$ and $1 \mathrm{~mL}$ of hydrogen peroxide $(30 \% \mathrm{v} / \mathrm{v})$ were added to $20-30 \mathrm{mg}$ of every sample and placed in a TFM digestion vessel. The vessels were closed and placed into the segment and the content was mineralized using an Ethos SEL Microwave Labstation (Milestone, Italy) at $220^{\circ} \mathrm{C}$, applying maximum power of $1000 \mathrm{~W}$. The microwave programme was started by steadily increasing the temperature over $15 \mathrm{~min}$, followed by holding the temperature for an additional $20 \mathrm{~min}$. After cooling, each resulting solution was transferred to $50 \mathrm{~mL}$ glass flasks and filled to the mark with deionized water.

Samples for assessment of $\mathrm{Ba}, \mathrm{Sr}$ and $\mathrm{Ca}$ were diluted with ionization buffer $(1 \mathrm{~g}$ lanthanum oxide, $1 \mathrm{~g}$ potassium chloride, $40 \mathrm{ml}$ nitric acid $(65 \% \mathrm{v} / \mathrm{v})$ and deionized water to a 1 I solution) and samples for assessment of $\mathrm{Zn}, \mathrm{Mn}$ and $\mathrm{Al}$ were diluted with deionized water prior to further analysis. Primary spectral lines were used for measurements of Ba (553 nm), Sr (460 nm), Ca (422 nm), Zn (213 nm), Mn $(279 \mathrm{~nm})$ and secondary spectral line for measurement of Al (396 nm). The content of Ba, Sr, Ca, Al was measured using nitrous oxide - acetylene flame atomization and $\mathrm{Zn}, \mathrm{Mn}$ content was measured using airacetylene flame atomization in a contrAA 700 atomic absorption spectrometer (Analytik Jena, Germany). All samples were measured in triplicate and the obtained values were processed by Aspect CS software, version 2.1. 
Table 1. Composition of reaction mixtures (concentration of sodium alginate $w_{\mathrm{ALG} N \mathrm{Na}}$ and molar concentration of crosslinking agents in water $c_{\text {ion }}$ ); number of crosslinking ions, as determined by atomic absorption spectroscopy, in alginate gels; and basic physical characteristics of crosslinking ions (molar weight $M$ and ionic radius $r$ ).

\begin{tabular}{lcccccc}
\hline Sample & $\begin{array}{c}W_{\text {ALG_Na, }} \\
(\%)\end{array}$ & $\begin{array}{c}\text { Crosslinking } \\
\text { agent }\end{array}$ & $\begin{array}{c}c_{\text {ion, }} \\
\left(\mathrm{mol} / \mathrm{dm}^{3}\right)\end{array}$ & $\begin{array}{c}w_{\text {ion, }} \\
(\mathrm{g} / \mathrm{kg})\end{array}$ & $r,(\mathrm{pm})$ & $\begin{array}{c}M \\
(\mathrm{~g} / \mathrm{mol})\end{array}$ \\
\hline ALG_Ba & 6 & $\mathrm{BaCl}_{2}$ & 1.0 & $379 \pm 4$ & 135 & 137.27 \\
\hline ALG_Sr & 6 & $\mathrm{SrCl}_{2}$ & 1.0 & $250 \pm 7$ & 113 & 87.62 \\
\hline ALG_Ca & 6 & $\mathrm{CaCl}_{2}$ & 1.0 & $209 \pm 5$ & 99 & 40.08 \\
\hline ALG_Zn & 6 & $\mathrm{ZnCl}_{2}$ & 1.0 & $207 \pm 6$ & 74 & 65.38 \\
\hline ALG_Mn & 6 & $\mathrm{MnCl}_{2}$ & 1.0 & $178 \pm 9$ & 67 & 54.94 \\
\hline ALG_Al & 6 & $\mathrm{AlCl}_{3}$ & 1.0 & $59 \pm 1$ & 50 & 26.98 \\
\hline
\end{tabular}

\section{Supporting Information SI3 - Morphology characterization}

Morphology characterization - Scanning Electron Microscopy (SEM) and Optical Microscope Analysis $(O M)$ : Particle size, morphology and surface topography were analyzed using SEM. To avoid charging artifacts, the samples were coated with a $10 \mathrm{~nm}$ thick layer of platinum/palladium $(\mathrm{Pt} / \mathrm{Pd})$ under argon atmosphere using the ion sputtering coating method. Pt/Pd was sputtered at a current of $20 \mathrm{~mA}$ for 20 s, $15 \times$ (Cressington sputter coater 208HR, England). The samples were anchored onto an SEM sample holder using carbon conductive double-sided adhesive discs (EMS, USA). Images were taken on a Hitachi SU8010 (Hitachi High-Technologies, Japan) scanning electron microscope at an accelerating voltage of $14.0 \mathrm{kV}$ for $40 \mathrm{~s}$.

Particle characteristics, i.e. equivalent diameter $(E D)$ and sphericity factor $(S F)$, were evaluated by using a NIKON SMZ 1500 stereoscopic microscope (Nikon, Tokyo, Japan) equipped with a 72AUC02 USB camera (The Imaging Source, Bremen, Germany). Particles were visualized under 15 -fold magnification. Images of 200 randomly chosen beads were stored and subsequently processed using the NIS-Elements AR 4.0 computer software (Nikon, Tokyo, Japan). ED and SF were calculated from the measured values and expressed as arithmetic mean and standard deviation (SD).

$E D$ was calculated according to the Eq. (1)

$E D=\sqrt{\frac{4 . A}{\pi}},[\mathrm{mm}]$

where $A$ is the area of the bead in square millimeters.

SF was calculated according to the Eq. (2)

$S F=\frac{4 \pi A}{p^{2}}$

where $A$ is the area of the bead in square millimeters and $p$ is perimeter of the bead in millimeters. 


\section{Supporting Information SI4 - Swelling Capacity}

To determine swelling capacity, a previously reported method was improved.[1] The test was performed in artificial gastric fluid (SGF, pH 1.2) and in phosphate buffer saline (PBS, pH 6.0) prepared according to Ph. Eur. 9. SGF was prepared by dissolving $2 \mathrm{~g}$ of sodium chloride and $7 \mathrm{ml}$ of concentrated hydrochloric acid in $1 \mathrm{~L}$ of ultrapure water. PBS was prepared by dissolving $6.8 \mathrm{~g}$ of sodium dihydrogen phosphate $\mathrm{R}$ in $1000.0 \mathrm{~mL}$ of water $\mathrm{R}, \mathrm{pH}$ adjustment with strong sodium hydroxide solution R.[2] The fed state simulated intestinal fluid ( $F S S I F, p H=6$ ) was prepared by dissolving $16.5 \mathrm{~g}$ of sodium taurocholate in 500 $\mathrm{mL}$ of blank FeSSIF (i. e. $20.2 \mathrm{~g}$ of NaOH, $43.3 \mathrm{~g}$ of glacial acetic acid, and $59.4 \mathrm{~g}$ of $\mathrm{NaCl}$ in $5 \mathrm{~L}$ of purified water, the $\mathrm{pH}$ was adjusted to 6.0 using $1 \mathrm{M} \mathrm{NaOH}$ ). The $59.1 \mathrm{~mL}$ of lecithin solution in methylene chloride $(100 \mathrm{mg} / \mathrm{mL})$ was prepared and the solvent was eliminated under vacuum at about $40^{\circ} \mathrm{C}$ for fifteen minutes at $250 \mathrm{mbar}$ and then for 15 minutes at 100 mbar. After cooling to room temperature, the volume was adjusted to $2 \mathrm{~L}$ by the blank FeSSIF addition. The test was carried out to mimic in vivo conditions of stomach and upper small intestine, respectively. One hundred milligrams of each sample were put into fine mesh baskets and immersed separately into $45 \mathrm{~mL}$ of each medium. The baskets were taken out at the time intervals of $0.5,1,2,3,4$ and $24 \mathrm{hrs}$ after the first immersion, properly dried and weighed. Swelling capacity was calculated using the following equation.[3]

$S_{S W}=\left(\frac{W_{t}-W_{0}}{W_{0}}\right) \times 100,[\%]$

where $S_{\mathrm{sw}}$ is swelling capacity expressed as a percentage of weight gain, $W_{\mathrm{t}}$ is the weight of the sample at the selected time interval and $W_{0}$ represents the initial weight of the sample. The measurement was performed in triplicate and results were expressed as mean values and $S D$.

[1] Lin W-C, Yu D-G, Yang M-C. pH-sensitive polyelectrolyte complex gel microspheres composed of chitosan/sodium tripolyphosphate/dextran sulfate: swelling kinetics and drug delivery properties. Colloid Surface B. 2005, 44 (2-3), 143-151.

[2] European Pharmacopoeia Commission et al. European Pharmacopoeia 9th Edition: Supplement 9.0, 4.1.3. Buffer solutions. Strasbourg: Council of Europe; 2017.

[3] Dai Y-N, Li P, Zhang J-P, Wang A-Q, Wei Q. Swelling characteristics and drug delivery properties of nifedipine loaded pH sensitive alginate-chitosan hydrogel beads. J Biomed Mater Res B. 2008, 86B (2), $493-500$. doi:10.1002/jbm.b.31046.

\section{Supporting Information SI5 - Dissolution Tests}

The dissolution test was performed in an automatic dissolution apparatus (SOTAX, type AT 7 Smart, Switzerland, Germany) at the $50 \mathrm{rpm}$ paddle speed in SGF (pH 1.2), PBS (pH 6.0) or FSSIF (pH = 6) as dissolution media $\left(37.0 \pm 0.5{ }^{\circ} \mathrm{C}\right)$. Each sample in the amount of $0.5 \mathrm{mg}$ was inserted into the vessel containing $500 \mathrm{ml}$ of the selected medium and dissolution medium in volume of $2 \mathrm{ml}$ was withdrawn in the $30,60,120,180,240,360,720$ minute intervals for assessment of ions content. The content of the individual ions $(n=3)$ was determined by atomic absorption spectroscopy (see Content of the Polyvalent lons in the Solid Beads for details) and results were expressed as mean values and SD. 


\section{Supporting Information SI6 - Ex-vivo Cytotoxicity}

Alginate beads (ca. $1 \mathrm{~g}$ ) were immersed into the D-MEM solution ( $9 \mathrm{~g}$ ) for 6 hours and extracted. After the extraction the re-dried alginate beads were analyzed by ss-NMR spectroscopy. In parallel, the obtained/residual D-MEM solution with extracted ions was used for cultivation of Vero cells. This way, toxicity of this solution was evaluated. This procedure when the cultivated cells were physically separated from the alginate beads (there was no physical contact between cells and substrate), was used to avoid unwanted contamination of alginate matrix by the cell material. This way we could analyze structural changes of alginate gels directly without artificial signals. It worthy to note that primary aim of our investigation was the analysis of structural changes of alginate gels at slightly basic conditions simulating intra- and extracellular environments. Subsequently, the cytotoxicity of the ions was tested on the Vero cell line. Vero cells $(10 \mathrm{e} 5 / \mathrm{mL}$ ) were suspended in a D-MEM (supplemented with $10 \% \mathrm{FBS}$ ) medium and $1000 \mu \mathrm{L}$ of cell suspension was seeded into a 24-well microtiter plate (Nunc). Serial tenfold dilutions of each individual ions in the same medium $(1000 \mu \mathrm{L})$ were added into a 24-hrold monolayer; nine wells per dilution. Subsequently, the cells were left to incubate at $37^{\circ} \mathrm{C}$ for 72 hours in a $\mathrm{CO}_{2}$ incubator. The number of viable cells after 24,48 and 72 hours of incubation were counted in the Bürker chamber using methylene blue (three wells for each dilution and each harvesting time) and compared with the number of cells in control wells containing only untreated Vero cells. Cell viability was expressed as the percentage of viable cells according to the following equation:

cell viability $=\frac{A \times 100}{B}$, [\%]

where $A$ represents the average number of viable cells in three wells with individual ions and $B$ is the number of cells from the control wells. The TC50 (50\% toxic concentration) value was determined at time points 24,48 and $72 \mathrm{hrs}$ as the first dilution of each ion that caused the $50 \%$ reduction of viable cells. 
Table 2. Composition of Dulbecco's Modified Eagle Medium (D-MEM).

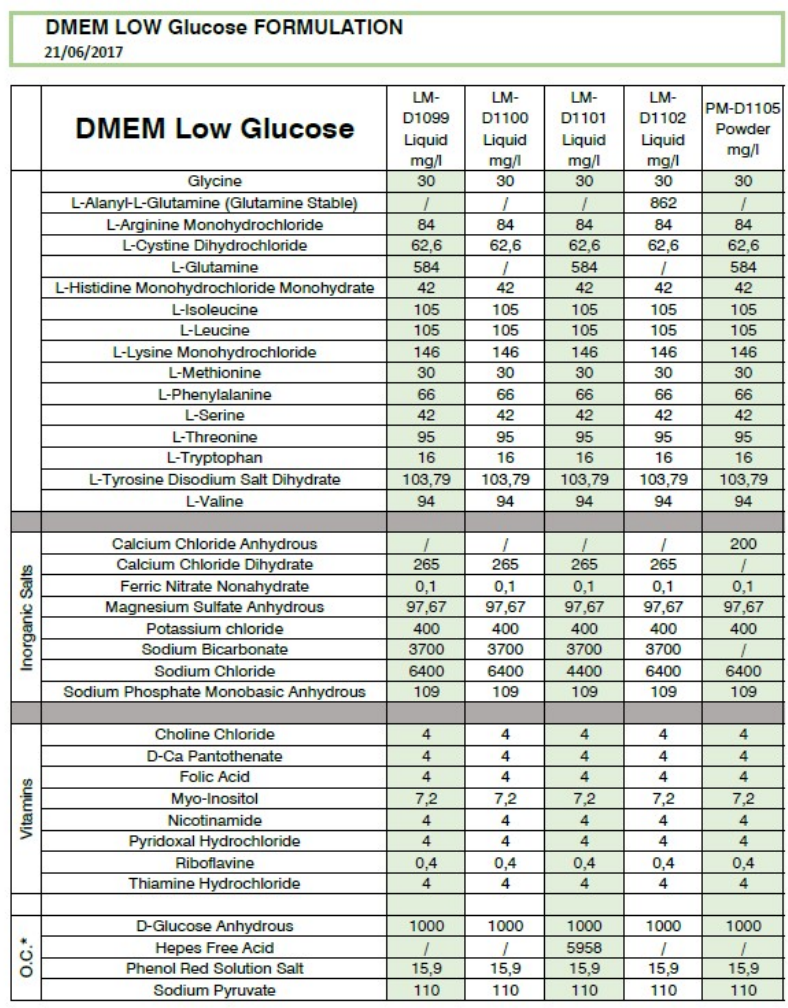

\section{Supporting Information SI7 - Solid-State NMR Spectroscopy}

All solid-state NMR spectra were measured at $11.7 \mathrm{~T}$ using a Bruker AVANCE III HD WB/US NMR spectrometer (Karlsruhe, Germany, 2013) in a double-resonance 4-mm probehead at spinning frequencies $\omega_{\mathrm{r}} / 2 \pi=11 \mathrm{kHz}$. In all cases finely powdered, macroscopically dry, samples were placed into $4-\mathrm{mm} \mathrm{ZrO} \mathrm{Zn}_{2}$ rotors. All experiments were conducted at $303 \mathrm{~K}$. Frictional heating of the rotating samples was compensated.

\section{Multinuclear CP/MAS and MAS NMR spectroscopy}

The ${ }^{13} \mathrm{C}$ CP/MAS NMR spectra employing cross-polarization (CP) were acquired using the standard pulse scheme at spinning frequency of $11 \mathrm{kHz}$. The optimized recycle delay was $2-4 \mathrm{~s}$ and the crosspolarization contact time was $1.75 \mathrm{~ms}$. The strength of spin-locking fields $B_{1}\left({ }^{13} \mathrm{C}\right)$ expressed in frequency units $\omega_{1} / 2 \pi=\gamma B_{1}$ was $64 \mathrm{kHz}$. The spectra were referenced to $\alpha$-glycine $(176.03 \mathrm{ppm})$. The number of scans was $1-2 \mathrm{k}$.

The single-pulse ${ }^{23} \mathrm{Na},{ }^{27} \mathrm{Al}$ and ${ }^{31} \mathrm{P}$ MAS NMR spectra were acquired at a spinning frequency of $11 \mathrm{kHz}$ with a pulse width of $1.0 \mu \mathrm{s}\left(30^{\circ}\right.$ flip angle); excitation field intensity $B_{1}\left({ }^{23} \mathrm{Na},{ }^{27} \mathrm{Al},{ }^{31} \mathrm{P}\right)$ of $83.3 \mathrm{kHz}$; recycle delays of 2-20 s; and the number of scans 64-1024 depending on the signal-to-noise ratio. 


\section{${ }^{1} \mathrm{H}$ CRAMPS NMR spectroscopy}

The ${ }^{1} \mathrm{H}$ CRAMPS NMR spectra with DUMBO homodecoupling were measured at $10 \mathrm{kHz}$ (MAS frequency) and number of scans 16-64. The $90^{\circ}\left({ }^{1} \mathrm{H}\right)$ pulse-length was $2.2 \mu \mathrm{s}$, power level for DUMBO shape pulse was $71 \mathrm{~W}$, DUMBO pulse length $32 \mu$ s and the number of loops for digital averaging was 4-8. All parameters were optimized on glycine (Figure S1) to reach maximum spectral resolution $\left(\Delta v\left(\mathrm{NH}_{3}{ }^{+}\right)=250\right.$ $\mathrm{Hz}$ and $\Delta v\left(\mathrm{CH}_{2}\right)=230 \mathrm{~Hz}$ ). The ${ }^{1} \mathrm{H}$ scale was calibrated with external standard - alanin (low-field $\mathrm{NH}_{3}$ signal at $8.5 \mathrm{ppm}$ and the high field $\mathrm{CH}_{3}$ signal at $1.2 \mathrm{ppm}$.

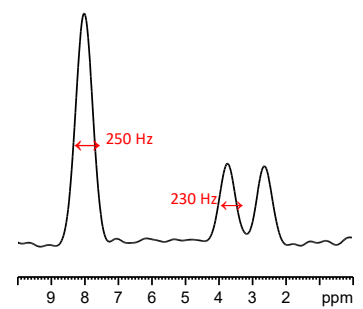

Figure S1. ${ }^{1} \mathrm{H}$ CRAMPS NMR spectrum $(10 \mathrm{kHz})$ of glycine.

2D ${ }^{27} \mathrm{Al}$ TQ/MAS NMR spectroscopy: The $2 \mathrm{D}^{27} \mathrm{Al} 3 \mathrm{O} / \mathrm{MAS}$ NMR spectra were measured at $12 \mathrm{kHz}$ (4$\mathrm{mm}$ probehead) using a three-pulse sequence with excitation, reconversion and selective pulse lengths of $4.2,1.5$, and $43 \mu \mathrm{s}$, respectively. The reconversion and selective pulses were spaced by a z-filter with a $20 \mu$ s duration. The hard pulse if intensity $\left.B_{1}{ }^{27} \mathrm{Al}\right)$ was ca. $100 \mathrm{kHz}$. The indirect $t_{1}$ evolution period representing spectral width of $27 \mathrm{kHz}$ consisted of 128 increments each made of 256 and 320 scans for ${ }^{27} \mathrm{Al}$ and ${ }^{23} \mathrm{Na} 3 \mathrm{O} / \mathrm{MAS}$ NMR spectra, respectively. The dipolar decoupling SPINAL64 was applied during data acquisition in both detection periods. 


\section{Supporting Information S8 - Scanning Electron Microscopy}
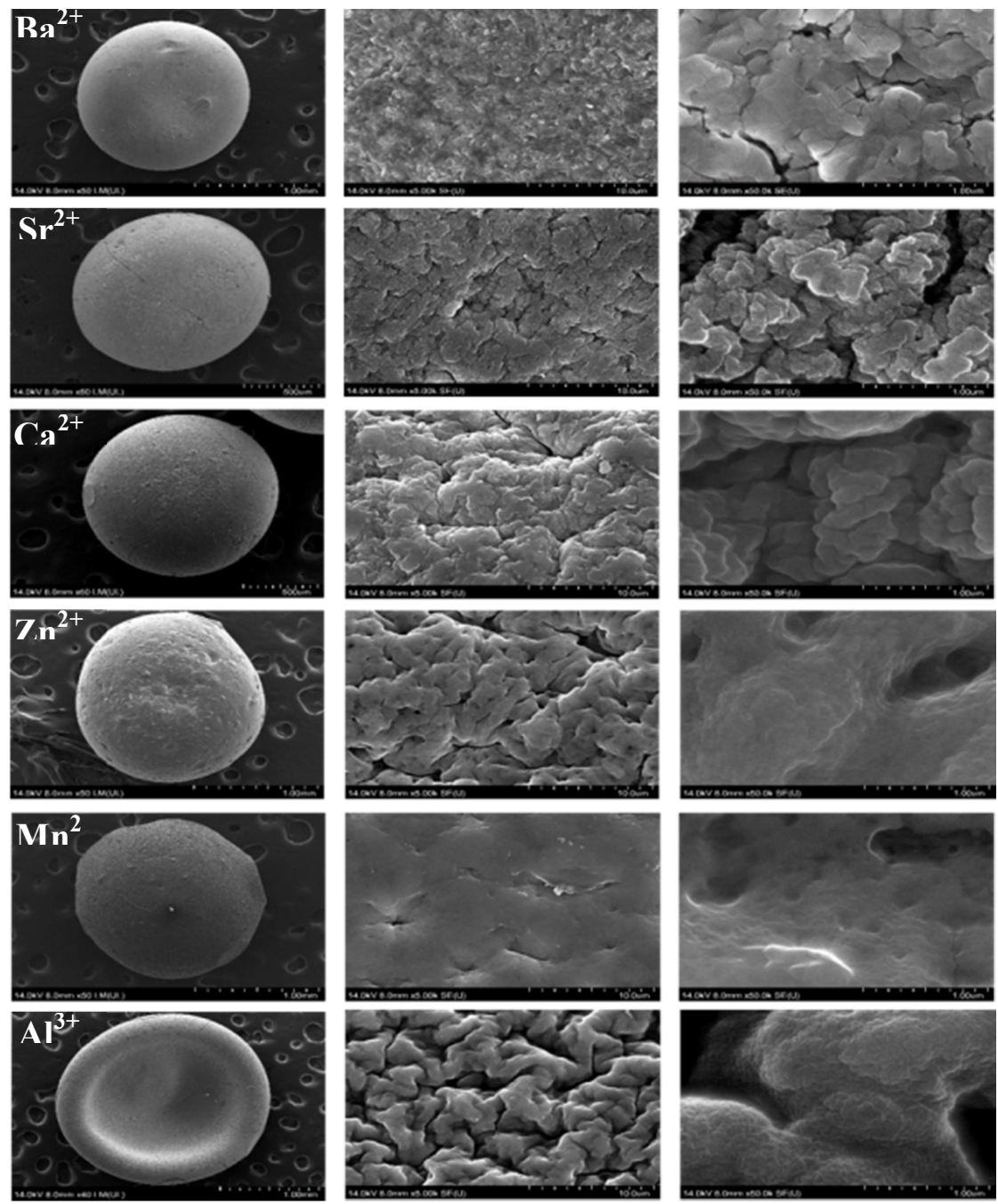

Figure S2. Alginate particles cross-linked by polyvalent ions visualized using SEM technique: whole particle (lefthand column), surface details (middle and right-hand columns). 